Hartmann, Ulrike; Decristan, Jasmin

\title{
Brokering activities and learning mechanisms at the boundary of educational research and school practice
}

formal und inhaltlich überarbeitete Version der Originalveröffentlichung in:

formally and content revised edition of the original source in:

Teaching and teacher education (2018) 74, S. 114-124

Bitte verwenden Sie in der Quellenangabe folgende URN oder DOI /

Please use the following URN or DOI for reference:

urn:nbn:de:0111-pedocs-181272

$10.25656 / 01: 18127$

https://nbn-resolving.org/urn:nbn:de:0111-pedocs-181272

https://doi.org/10.25656/01:18127

\section{Nutzungsbedingungen}

Dieses Dokument steht unter folgender Creative Commons-Lizenz: http://creativecommons.org/licenses/by-nc-nd/4.0/deed.de - Sie dürfen das Werk bzw. den Inhalt unter folgenden Bedingungen vervielfältigen, verbreiten und öffentlich zugänglich machen: Sie müssen den Namen des Autors/Rechteinhabers in der von ihm festgelegten Weise nennen. Dieses Werk bzw. dieser Inhalt darf nicht für kommerzielle Zwecke verwendet werden und es darf nicht bearbeitet, abgewandelt oder in anderer Weise verändert werden.

Mit der Verwendung dieses Dokuments erkennen Sie die Nutzungsbedingungen an.

\section{Terms of use}

This document is published under following Creative Commons-License: http://creativecommons.org/licenses/by-nc-nd/4.0/deed.en - You may copy, distribute and transmit, adapt or exhibit the work in the public as long as you attribute the work in the manner specified by the author or licensor. You are not allowed to make commercial use of the work or its contents. You are not allowed to alter, transform, or change this work in any other way.

By using this particular document, you accept the above-stated conditions of use.

\section{Kontakt / Contact:}

\section{peDOCS}

DIPF | Leibniz-Institut für Bildungsforschung und Bildungsinformation Informationszentrum (IZ) Bildung

E-Mail:pedocs@dipf.de

Internet: www.pedocs.de

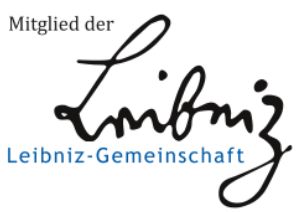




\title{
Brokering Activities and Learning Mechanisms at the Boundary of Educational \\ Research and School Practice
}

Ulrike Hartmann $^{\mathrm{a}, \mathrm{b},{ }^{*}}$ \& Jasmin Decristan ${ }^{\mathrm{a}, \mathrm{b}}$

\begin{abstract}
Affiliations
${ }^{a}$ University of Wuppertal, Germany

${ }^{\mathrm{b}}$ German Institute for International Educational Research, Frankfurt am Main, Germany

* Corresponding author
\end{abstract}

\section{Contact Information}

Corresponding author:

Ulrike Hartmann

Gauss Str. 20

42119 Wuppertal, Germany

e-mail: uhartmann@uni-wuppertal.de

phone: +49 (0)202 / 439-3741

Jasmin Decristan

University of Wuppertal

Rainer-Gruenter Str. 21

42119 Wuppertal, Germany

e-mail: decristan@uni-wuppertal.de

phone: +49 (0)202 / 439-1269

German Institute for International Educational Research

Department for Education and Development

Department of Educational Quality and Evaluation

Schlossstraße 29

60486 Frankfurt am Main, Germany

Funding: This work was supported by the Robert Bosch Foundation (Grant No:

12.5.4000.0236.0) 


\section{Abstract}

The interview study explores in what kind of settings people broker at the boundary of educational research and school practice and what kind of learning they experience. Learning mechanisms (identification, coordination, reflection, transformation) were related to three settings (research projects in schools, network activities, professional development). Responses by 18 individuals indicate that all three settings allowed for learning via identification, reflection, and coordination. Still, respondents that solely broker in the setting of professional development were less likely to learn via all three mechanisms. Transformation was only realized in settings that enabled people to establish forms of joint project work.

\section{Keywords}

Boundary Crossing, Partnerships in Education, Evidence Based Practice 
Researchers, policymakers, funders, and practitioners often bewail a wide gap between educational research and day-to-day school practice. The underlying reasons for this gap are manifold, ranging from shortcomings in presenting scientific findings to broader public and professional communities (e.g., Kaslow, 2015; Shonkoff \& Bales, 2011), problems concerning the selective uptake of evidence (e.g., Coburn, Honig \& Stein, 2009; Prewitt, Schwandt \& Straf, 2012), to serious doubts about the appropriateness of an assumed linear process of transfer from research to practice settings (e.g., Coburn \& Stein, 2010; Hammersley, 2013; Penuel, Allen, Coburn, \& Farrell, 2015), just to name a few strands of the current debates.

As researchers and practitioners are members of distinct communities of practice (Wenger, 1998), each of them with their professional identities that have been formed over time, a transfer of research findings seems not likely to happen easily since the content being transferred needs to overcome professional boundaries between the field of educational research and school settings. Addressing this challenge, research has turned to investigating efforts that try to connect educational research and school practice on a level of interpersonal contact between representatives of both fields (Nutley, Walter, \& Davis, 2007). These attempts specifically address the need for interaction and communication. The associated assumption is that when people collaborate at the intersection of research and practice, joint learning may enhance the permeability of the constituent boundaries and increase the chance that scientific evidence is adapted to enhance teaching practices and vice versa (e.g., Akkerman \& Bruining, 2016; Coburn \& Penuel, 2016; Penuel et al., 2015). Cochran-Smith and Lytle (1999) have emphasized this need for collaborative efforts between educational science and schools to result in a ,knowledge-of-practice' - a form of knowledge that is neither solely research- nor practice-based, but integrates both strands. The authors argue that this kind of knowledge can best be developed when people from both educational research and school practice are regarded as learners that form a community of inquiry. The ultimate goal is then to understand, articulate, and alter practice to make fundamental changes in classrooms and schools (Cochran-Smith \& Lytle, 1999).

Accordingly, research on collaborative work has gained increased attention within the last years to implement new methods that are practically relevant as well as scientifically rigorous to improve learning and instruction in schools (e.g., Anderson \& Shattuck, 2012). In their recent review, Coburn and Penuel (2016) suggest several key features that should be realized in Research-Practice Partnerships (RPPs), including a long-term perspective, concentrating on 
problems of practice as a starting point, a jointly negotiated focus, employing intentional strategies to foster partnerships including routines, rules, and roles for a structured interaction (see also Jones et al., 2016; King et al., 2010; Metzler et al., 2003). Since such long-term partnerships require a large monetary, structural, and social investment on the part of the involved parties and the funding institutions, the authors address the need for research into their potential outcomes. However, there is only relatively little evidence, either on the realization of partnerships that live up to these criteria, or on their impact on the learning processes of the participants (e.g., Brown, Hawkins, Arthur, Briney, \& Fagan, 2011; see Coburn \& Penuel, 2016 for a review).

In Germany, as the context of this study, systematic partnerships between educational research and school practice are only starting to become a matter of broader interest. Thus, there are quite differing states of personal cooperation between educational researchers and teachers. Personal contact between researchers and teachers mostly depends on the interest of individuals, or the presence or absence of any local or state-wide initiatives. Lacking a formalized structure to organize interpersonal collaboration, the literature has revealed the important role of individual people to establish a link between two fields of practice (Akkerman \& Bakker, 2016). These actions can take various forms and are often conceptualized as brokering or boundary crossing activities.

Taken together, the literature points to a gap between educational research and school practice, and has suggested that interpersonal contact between representatives of the two fields may be one lever to reduce it. Therefore, it seems crucial to know more about the potential benefits that individuals can draw from their boundary crossing experiences. Moreover, as research on RPPs indicates that partnerships should fulfill strong criteria (e.g., mutuality and sustainability) to be successful, it seems questionable what kind of success for the participating individuals can be expected in the various settings of interpersonal boundary contact that are currently realized - bearing in mind that many of these settings are far from fulfilling these criteria. Accordingly, the study addresses the contextual conditions under which professionals from teaching practice and educational research use opportunities for indvidual brokering activites. It tries to answer what kind of contextual conditions relate to the learning potential of boundary crossing that many authors have proposed (see Akkerman $\&$ Bakker, 2011, for a review). Using the theoretical framework of cultural historical activity theory (CHAT) (e.g., Engeström, 1987), potential outcomes of brokering activities at the 
interface between research and practice at the level of the participating individuals are the focus of this study.

\section{Learning Mechanisms at Professional Boundaries}

Viewing contact between educational research and school practice as occasions when dialogue and joint learning may occur, the concepts of boundaries and boundary crossing provide a possible source for a detailed investigation. Relating to approaches from cultural historical activity theory (Engeström, 1987), a boundary can broadly be conceptualized as "a socio-cultural difference leading to discontinuity in action or interaction" (Akkerman \& Bakker, 2011, p. 133). Applied to encounters between representatives of different professional communities with separate socio-culturally established histories of expertise (e.g., Edwards, 2012), boundaries constitute the inherent differences between those professions. Suchman (1993, p. 25) describes boundary crossing as a process of individuals entering "new territory in which we are unfamiliar and, to some extent therefore unqualified". At the same time, boundaries provide opportunities for overcoming discontinuities in action when people successfully cross them. Relating to their review on 181 studies on boundary crossing, Akkerman and Bakker (2011) have emphasized the potential outcomes of this endeavor in terms of learning at the boundary. Viewing learning in a "very broad sense, including new understandings, identity development, change of practices, and institutional development" (p. 142), they have outlined four separate learning mechanisms, labeled identification, reflection, coordination, and transformation.

(1) Identification refers to the definition of one specific practice, delineating how it differs from another practice, a process called othering. Moreover, a second process constitutes identification, a process called legitimating coexistence, meaning that an individual can consider both practices to differ from each other, with each providing their own intrinsic value and specific contribution.

(2) Coordination refers to activities at the boundary that aim to make joint work more efficient, and facilitate a continuous movement between different sites. It entails establishing a communicative connection, e.g., by means of translation efforts, and enhancing boundary permeability from both sides. Finally, routinization processes in work between two sites of practice characterize the learning mechanism of coordination.

(3) Reflection, as a third learning mechanism, builds on identification processes in a way that allows subjects to recognize differences between practices and relate them to the bidirectional perceptions of the participants in a boundary crossing endeavor. Reflection involves making 
one's own perspective explicit, and reflecting it in the light of the other perspective, while at the same time taking the other perspective into account for a more thorough understanding of a problem.

(4) The fourth learning mechanism is labeled transformation. It is assumed to lead to profound changes in practice, potentially creating new independent practices that comprise elements from two different fields in a hybrid manner. Based on their review of empirical findings, Akkerman and Bakker (2011) describe transformation as a process that is initiated by individuals or systems that are confronted with a problem at the boundary, and a subsequent recognition of a shared problem space by the involved parties. To overcome the problem in a joint action, measures are taken to establish hybrid practices and embed them into collaborative routines so that continuous dialogical work at the boundary can be maintained.

Akkerman and Bakker (2011) summarize that while identification and reflection are more meaning-oriented processes, coordination and transformation are constituted by specific actions of the involved parties. Notably, the four mechanisms are not fully independent from each other, as reflection builds on identification, and reflection on differences between separate practices would appear necessary in order to establish any transformative learning. Even though the learning mechanism of transformation generates so-called hybrid practices, it does not imply that practices merge completely as a result of transformation. Each practice remains stable in its respective core, while coordinative and transformative practices permit the boundaries to become more aligned with each other and establish continuous dialogue reflecting mutual expectations (e.g., Akkerman \& Bakker, 2011; Edwards \& Stamou, 2017).

\section{The importance of brokering activities}

The process of boundary crossing is inherently difficult for individuals because it requires them to enter new territory and thus implies feelings of uncertainty in the face of unfamiliar actions (Suchman, 1993). At the same time, individual boundary crossing activities are crucial in situations where no formalized structure of collaboration between two fields of practice has been established yet (Akkerman \& Bakker, 2011). The term brokering is used to describe efforts of individual people to span across boundaries and to establish continuity in action and interaction. People can become permanent brokers describing their structural position in a network - e.g., as a research coordinator in a school disctrict. But brokering activities can also start with temporal actions that people engage in to do boundary crossing work. Many authors 
have reflected on the ambiguity associated with brokering, describing conflicts of accountability and belonging to each field of practice (e.g., Tanggaard, 2007; Edwards, Lunt \& Stamou, 2010). At the same time, brokers can be appreciated for their innovative role in changing professional practices (Jones, 2010). Research from the field of education suggests that for joint learning to be successful, individual and contextual characteristics play an important role in facilitating activities of brokering (Bakx, Bakker, Koopman, and Beijaard, 2016). Following this line of argumentation, brokering activities by researchers and practitioners that result in joint learning may help in reducing the gap between educational research and school practice.

\section{Personal requirements for boundary crossing: Common knowledge, relational expertise, and relational agency}

Research has identified crucial capabilities of individuals and groups that facilitate successful boundary crossings and continued joint work. Walker \& Nocon (2007) propose that individuals need boundary crossing competence, meaning the "ability to manage and integrate multiple, divergent discourses and practices across social boundaries" (p. 181). Edwards $(2012$; 2017) elaborates on three required characteristics of the partners - common knowledge, relational expertise, and relational agency - as being necessary to navigate the tensions that are associated with working at boundaries. To be capable of relating two fields (e.g., research and practice) to each other, the mechanism of identification seems to be a necessary prerequisite (identifying one's own role and the professional role of the other). Furthermore, relational expertise (recognizing what others can offer in a shared enterprise, while also being able to work with what others offer and making visible and accessible what matters to you) seems necessary to achieve any kind of reflection. Subsequently, it requires relational agency (e.g., aligning one's own responses on enhanced interpretations as part of a collaboration) to engage in any transformative processes that require communication across practices and the establishment of new tools for sustained collaboration. Providing empirical support for the facilitating role of these individual competencies, Bakx et al. (2016) interviewed teacher researchers who were qualified in a $\mathrm{PhD}$ program on science education. The authors identified two out of sixteen respondents as particularly successful brokers and identified personal characteristics that contributed to continuous boundary crossing activities of these individuals. Successful brokers were equipped with an ability to flexibly shift between the two sides, indicating communication and interaction skills that can theoretically be linked to what Edwards (2012) conceptualized as relational expertise and relational agency. Moreover, the authors identified successful teacher researchers as being highly pro- 
active (taking the initiative on their own and recognizing opportunities for boundary crossings).

\section{Context conditions for establishing brokering activities}

Looking at contextual factors, Coburn and Penuel (2016) suggest several key features that should be realized in Research-Practice Partnerships in education (RPPs), including a longterm perspective, concentrating on problems of practice as a starting point, a jointly negotiated focus, employing intentional strategies to foster partnerships including carefully designed routines, rules, and roles for a structured interaction. The study of Bakx et al. (2016) found that an open school climate, enough time to align research and school activities with each other, and a certain research-mindedness of the school team helped teacher researchers to fulfill brokering roles. These factors can also be regarded in relation to the learning mechanisms of Akkerman and Bakker (2011), as specifically coordination may help to align research and practice activities more efficiently to navigate the inherent tensions for the participating individuals.

A body of research emphasizes the sustainability of cooperation and partnership as crucial for successful boundary crossing (e.g., Edwards \& Stamou, 2017; Sannino \& Engeström, 2017). Continuous collaborative practices can serve as precursors as well as mediators for successful boundary crossings. Penuel et al. (2015) emphasize the need for sustainable cooperation, since joint work at boundaries does not fit easily into any of the partners' primary institutional roles and responsibilities - indicating that brokering activities are mostly executed as an addon to the primary function of being a teacher or a researcher. As boundary crossing conceptually refers to "ongoing two-sided actions and interactions between contexts" (Akkerman \& Bakker, 2011), Coburn \& Penuel (2016) suggest that partnerships in education should be conceptualized as long-term collaborations to address persistent problems of school practice, to continually facilitate brokering activities. Akkerman and Bruining (2016), studying a professional development school partnership over five years, found that the four learning mechanisms (identification, coordination, reflection, and transformation) related to different phases of partnerships - coordination being more prominent at the outset of the partnership, whereas transformation occurred in later years.

Apart from the duration of a partnership, Sannino (2016) found that the composition of individuals is furthermore critical for the success of joint work, as well as a shared object of work is needed to engage in successful boundary crossing (Sannino \& Engeström, 2017), mirrored by Coburn's and Penuel's (2016) requirement of a jointly negotiated focus. Coburn, Penuel, and Geil (2013) identify at least three distinguishable forms of intense collaboration 
between educational research and practice, being local/regional research alliances, Design Research, and Network Improvement Communities, all involving a long-term perspective with a core of individual participants who are committed to the partnership for the whole time of the project. Edwards \& Stamou (2017) found that researchers distinguished between network and partnership activities. For partnerships, co-constructive relationships with practitioners around a shared problem were emphasized, whereas networks were regarded as "providing fertile ground for these relationships" (p. 275).

\section{Purpose of the study}

Taken together, joint learning at the boundary of educational research and school practice is most likely to emerge when certain conditions are met. Various individual and contextual factors are at play to facilitate the alignment of educational research and school practice in productive ways. Executing brokering activities by individuals seems to be especially important in fields where a formalized structure of collaboration is lacking. As reviewed above, Coburn and Penuel (2016) have proposed several criteria for successful partnerships between educational research and practice that may facilitate brokering activities. Many of these criteria cannot be taken for granted as they require large investments on both sides to be implemented and sustained. Therefore, our empirical investigation aims to answer how specific contextual conditions of interpersonal contact that are currently being realized are related to the emergence of learning mechanisms.

Specifically, the study aims to answer the question, in what kind of settings people execute brokering activities at the intersection of educational research and school practice. Further, we aim to investigate how these different settings relate to the emergence of specific learning mechanisms for the brokering individuals. The aforementioned categories of learning mechanisms laid out by Akkerman and Bakker (2011) are used to classify the potential benefits that interpersonal contact can entail for the participating individuals.

\section{Methods}

\section{Project and sample}

The data for this study were collected from the participants of a project that addressed the viewpoints of educational researchers as well as teachers on issues of learning and instruction in school. The aim of the project was to compare and discuss perspectives on the interface of 
educational research and school practice. We addressed subjects from both research and practice that were interested in participating in a dialogical workshop with representatives from both fields, and who were willing to share their experiences at the boundary in an interview, prior to that workshop. The project's goal was to have an equal number of researchers and practitioners in the sample, and to include a variety of individual and contextual characteristics in our sample, and not to narrow the project down to a specific research field or school subject. A further criterion for participation was professional expertise, which resulted in choosing only professors as researchers, and teachers with substantial job experience. From approximately 35 people we invited, we report on the interview data of 20 persons that finally participated in the project. Ten researchers in the field of education (professors in educational science, educational psychology, and teacher education) participated in the project. Four were female, mean age was 53 (range from 40 to 73 years), mean professional experience was 23 years. Ten teachers from different school tracks (elementary schools, different forms of secondary schooling) participated. Three of the interviewed teachers held a principal or assistant principal position in their schools. Teachers (six female) averaged 51 years old (range from 35 to 61 years), with a mean professional experience of 17 years.

All subjects participated voluntarily in the interview. Ethical approval for the study was obtained by the institute's ethics committee. Participants were asked for written consent prior to participating in the interview. Adherence to the regional and federal privacy protection guidelines, including anonymity in all publications was assured. All references in the interviews to concrete projects, names of colleagues, cities etc. were anonymized as part of the transcription process. For the presentation of the analyzed data of this small-scale study, the strict obedience to these requirements resulted in the decision against revealing individual combinations of age, gender, and professional experience for each respondent to secure the anonymity of our participants.

\section{Semi-Structured Interviews}

The interview addressed the interfaces between educational research and school practice from the first-hand experience of the respondents. Respondents were first asked how important they considered educational research resp. school practice in their day-to-day practice. They were further asked whether and how they communicated with the respective other group, and what kinds of challenges they experienced at the interface. They were also prompted on specific situations in which they had experienced a fruitful dialogue or cooperation between 
research and practice. The interviews lasted approx. 50 minutes each. The authors of this paper conducted roughly $60 \%$ of the interviews themselves. $40 \%$ were conducted by two research assistants who were trained to adhere to the same written interview guideline. All participants received a short questionnaire immediately after the interview for some demographic information (age, sex, qualification, and professional experience).

\section{Coding Procedure and Analysis}

The interviews were audio-taped and were transcribed by an external agency in accordance with the standard transcription guidelines by Dresing and Pehl (2013).

\section{Forms of interpersonal contact at the boundary.}

Each transcript was analyzed by the first author and a research assistant to assess the forms of interpersonal contact that the participants reported on. Against the background of the literature on RPPs (Coburn \& Penuel, 2016), and on literature on boundary activities in the field of research and practice (Akkerman \& Bruining, 2016; Edwards \& Stamou, 2017), we followed an iterative coding procedure to include theoretical elements as well as elements of inductive data analysis. Most mentions fell into three categories of interpersonal contact at the boundary, being research projects in schools, network activities, and professional development activities. Throughout the course of the analyses, the first category could be further subdivided into researcher-led projects and joint projects between researchers and practitioners. Some other forms of interpersonal contact at the boundary were mentioned only in very few cases. These are described in the last column of table 1.

In two of the transcripts by teachers, no interpersonal contact at the boundary was mentioned, nor could it be inferred from the narrations throughout the interview. Their experiences at the interface merely consisted of reading texts by researchers without being in touch with them on a personal level. We therefore had to exclude these two transcripts from all subsequent analyses.

\section{Learning mechanisms.}

To answer the research questions, we analyzed the interviews using qualitative content analysis (Dresing \& Pehl, 2013; Kuckartz, 2014) to identify learning mechanisms that participants expressed when reporting activities at the boundary between educational research and school practice. In so doing, we followed a deductive coding scheme applying the four categories of learning mechanisms (Akkerman \& Bakker, 2011; Akkerman \& Bruining, 2016) 
of Identification, Coordination, Reflection, and Transformation. The authors of this paper coded all material independently from each other. Codes were applied to all excerpts in which participants reported their own experiences at the boundary between research and practice. The initial coder agreement was computed on the basis of $30 \%$ of the material and amounted to $75 \%$. Coding units over which coders disagreed were mutually discussed to reach an agreement. The coding scheme with examples from the four categories is presented in table 2 . During coding, we recognized that for the mechanism of transformation, we found narrations where the mechanism was addressed, but not directly related to the participants' own experiences. Rather, participants formulated a transformation as a benefit that they anticipated if contact between research and practice was to be established or intensified. These instances were therefore coded with a supplementary coding: 'wish for transformation'.

\section{Results}

\section{Settings for interpersonal contact at the boundary}

The analyses include the 18 respondents that reported having at least one form of personal contact at the boundary of educational research and school practice. All subjects reported instances of Professional Development at the boundary. For six of them, this was the only form of interpersonal contact they experienced. Six of the participants were involved in research-practice related network activities, and also six were involved in at least one joint research-practice project. Four respondents reported on their participation in project work that were mainly researcher-led. Moreover, three of the researchers reported on own activities in counselling work for schools. Table 1 shows the individual combinations of the three main forms of interpersonal contact at the boundary (i.e., research projects in schools, network activities, and professional development).

Table 1 further indicates that the learning mechanisms our respondents reported on were not distributed equally across the subjects, but came along with the setting in which they executed brokering activities. Relations between interpersonal contact and learning mechanisms are reported below, structured by the three main categories of interpersonal contact. Providing excerpts from the interviews, we elaborate on how specific contextual conditions relate to the appearance of learning mechanisms. By doing that, we aim to clarify how the setting in which people broker enables them to learn at the boundary in various ways. 


\section{Research projects in schools}

Research projects in schools constitute one opportunity for educational researchers and teachers to directly work at the boundary. Additional to their genuine research foci, being in schools can provide researchers with insights into the working conditions of teachers in schools, into classroom discourse, into children's learning processes, and so forth.

Complementary, by participating in research projects, teachers can grasp what kind of issues are important for educational researchers, and gain insight into observing research methodology at work. Ten of the subjects talked about participating in research projects as a context for brokering activities between educational research and school practice. Out of these ten people, nine showed identification, and nine expressed reflection as a learning mechanism. All ten reported aspects of coordination. Five of the subjects that reported on project work expressed transformation as a learning mechanism (see table 1).

When researchers and teachers talked about research projects in schools, huge differences in the set-up of these projects came to the fore. From the nine respondents that reflected on project work, four reported projects that were mainly researcher-led. In these projects, the mechanism of coordination was central to achieve an efficient working arrangement for both sides, which did not burden the partners with too much extra work and effort. A teacher reports on several projects that are being conducted at her school, and highlights one project that was successful in achieving a balance in giving and taking for the researchers and the teaching staff.

“This research institute (...), for example. They say: 'Ok. We would like to come and try something out in your school, and as a compensation, we can provide you with a professional development course for the teaching staff on current issues of our work on children with German as a foreign language.' For me, that is a good deal, since I am responsible for managing the PD budget in our school. Then I don't have to take money from that, and still get a PD course for the whole staff. Perfect!'” (Transcript No. 12, lines 430-435).

The mechanism of coordination is also present in a larger long-term project conducted by a researcher including several schools, as the following excerpt shows.

"We are trying/Well, this is a necessary condition that we somehow establish a good connection with them [the schools]. But that is not easy. Our coordinator, she works day and night/ she has to make phone calls and emails and so on. This is a huge, complex thing. But, what we always try is to make them understand that we actually see each other as partners, but not on the... with the same skill-sets. So that it is actually clear that they have the skills to deliver lessons, to advise the students and so on. And we have the research skills. And you cannot meddle with that, you see? So, that's clear. (...) we know they are all very busy, but we absolutely need these data. (...) But we can't force them to do it. So, we try to achieve a partnership with them." (Transcript No. 2, lines 648-660). 
A strict division of research and practice remains visible in this excerpt, a feature that is constituent for the mechanism of coordination. Identifying what each side is responsible for ("they have the skills to deliver lessens, ..." and reflecting on the mutual expectations ("We know they are all very busy...But we can't force them to do it.") are present in the statements of this researcher. These learning mechanisms are used to account for the need for coordinative efforts to keep the project on track.

In these researcher-led projects, sometimes instances of single elements that reveal more of a co-constructive endeavor between the involved researchers and the teachers become visible. In this case, participants may realize an opportunity for joint learning in a transformative way - as the following excerpt by a teacher illustrates. Having had several researcher-led projects in her school, she expresses an increasing wish for transformative practices after discussing with a researcher the data that were collected as part of a project, and after realizing a benefit from such a discussion.

"What I would appreciate is for research to be more in schools. Well, really research projects like the one we had last year, when someone comes into school and actually conducts a project in our regular classes. Not that I'm handing over my class and he does something spectacular with that class, but that/ that regular classes are not just really observed and analyzed, but in an exchange with the teachers. Because I really believe that research could yield so much that educational practice could benefit from. We are simply not getting this now." (Transcript No. 15, lines 332-339).

In contrast to these researcher-led projects, the responses of subjects that work in joint projects show the mechanism of transformation not merely as a wish, but as something that is being realized in their work. Often, these joint projects contained joint data analyses by researchers and teachers, i.e., mutual reflection and discussion of videos from classroom situations. Five of the respondents report on such a setting for their individual brokering activities. The following researcher (transcript No. 7) describes a setting in which material from pedagogical practice (video tapes of classroom situations) is jointly analyzed by teachers and himself.

"Well, there are situations that I find particularly inspiring - which is when I am actually doing the same with the teachers as what I do with students or with my colleagues in a research group: working with material from pedagogical practice. Well, that is a format that forces you to concentrate on just that one situation. It is a joint point of reference. And you can discuss in advance 'What does this situation stand for?' To get into an exchange about it (...) this is what I find very/ this is what I find productive. Well, it has/ I just find, it makes clear that you need a certain reflexivity (...) and this is a joint basis, because you really always have to start to jointly analyzing this material". (Transcript No 7, lines 840-851). 
Transformation in these projects builds up on the mechanism of identification and reflection (see table 1).

Another researcher who engages in a long-term practice contact conducting joint work also expresses this transformative aspect on a personal level.

"[Through this joint project] I get a deep insight into how these teachers work, what is important for their instructional practices. And they also have their specific ideas on [research topic], and what such a student learning task should look like/ what you could do. Ideas that I wouldn't have had myself. (...) And then they try it out in their classes, and after that we meet again and reflect on it... These are projects in which I have the feeling that it is a true exchange. And there, I'm not like the researcher who comes and tells the teachers what to do. Well. And that really works out so well. (...) Well, I can only speak form myself: Well I certainly gain something from that. Before I go there, I always think: Oh, I already have to go there again (...) When I am there, and when I go home afterwards, I think: Oh great! This has grounded me, yes, I get in touch with practice, yes, by such an extensive exchange with teachers about their instructional practice."

(Transcript No. 8, lines 489-500).

In this excerpt, it becomes apparent how identification and reflection ("I get a deep insight into how these teachers work, what is important for their instructional practice"), and coordination (shown by a context that brings researchers and practitioners together regularly: "I already have to go there again") may lead to aspects of transformation ("ideas that I wouldn't have had myself... a true exchange"). At the same time, this researcher provides an insight into the conditions that are crucial for doing brokering work at the boundary between educational research and school practice, as the following excerpt shows:

"I need contact with school practice. And what I would like to add: (...), well, a small amount of it. Really, homeopathic dosage - not every week, but I do need regular contact with practice. Which means I do need to enter a school building once in a while, and walk around there. And I need to go into a classroom from time to time. I would never/ I found it problematic, for example, having your data collected only by the research assistants." (Transcript No. 8, lines 543-548).

The aspect of dosage is also reflected in the statements of many other respondents. As boundary work in joint projects requires a large amount of personal resources, all emphasize time limitations as a crucial factor that keeps them away from brokering activities. When time and effort seem manageable, brokering is more likely to occur.

"And then she [a researcher] comes for an hour, provides some input on what she saw in the data. And we [the teachers] also report, how did we come up with those rubrics? How did we develop them? (...) and these are time frames that are manageable. I can attend a working group once a month/I can go there for an hour to meet someone. It can be an afternoon once in a while." (Transcript No. 15, lines 475-481). 


\section{Network activities}

Working in networks characterized the professional context of six participants in this study. For the researchers, networks mostly consist of one or a few departments of their university, and a larger amount of cooperating schools - organized either regional or state-wide. For teachers, the networks mentioned were larger communities of schools, into which researchers were invited occasionally for external advice or input, e.g., in the form of scientific talks or school visits.

All respondents working in networks report mechanisms of identification, coordination, and reflection while working at the boundary. They emphasize how being part of networks facilitates access to the 'other' side, and provides opportunities for regular exchange.

"In this network, we meet twice a year for a joint event, a forum, where all participating schools are invited. (...) And where we we provide an input from instructional research, school research, and discuss with teachers what this means for practice. And this is an example for - where you can on the one hand/What I really appreciate is to get feedback from school practice very quickly whether this is useful knowledge to them, and how you present this knowledge to them. (...) And I recognize an openness in them to be up-to-date, and to know about what we can really say from research, and what we do not know yet. And at the same time, these occasions provide an input for future research, because the teachers come up with questions that they are concerned with at that moment. Well, so you gain something and create something new." (Transcript No. 10, lines 392-408).

The learning mechanisms of identification, reflection, and coordination are reflected in this quote. While the "forum" taking place twice a year is likely to be a result of coordination at the boundary, it supports mutual identification ("we provide an input from instructional research... And I recognize an openness in them to be up-to-date") and reflection ("the teachers come up with questions that they are concerned with at the moment. Well, so you gain something and create something new") on both sides. However, as in the researcher-led projects mentioned above, a strict division of labor remains. While three learning mechanisms (identification, reflection, and coordination) are present in the responses of the interviewees, no aspects of transformation are reported.

Being part of a network may also enhance further brokering activities that again provide opportunities for learning mechanisms to emerge. As a member of a school excellence network, this teacher subsequently became a member of a board of editors of a practiceoriented journal set up by several researchers. 
"And now, a new journal has been set up. (...) And I'm now a member of the editorial board. And overall, there are many theorists, well, emeritus professors. [...] And they have specifically chosen me to participate, as a practitioner from a school, you know? (...) And for me, both are important, you know? So, I kind of need empirical educational research. Or I need research to say, somehow, what can we-well - from lots of different studies/ What has actually been found out about how students learn best?" (Transcript No. 13, lines 438-445).

Regarding the set-up of network activities, respondents differ with regard to intensity and mutual obligation. A researcher embedded in a school-university network in which each of the partners is responsible for certain aspects of the partnership reports on his brokering activities. In this extensive form of network activity, identification, reflection, and coordination enable the fourth mechanism of transformation to emerge, as the following three quotes illustrate.

„And these are not just any schools in which our university students do their practical training, but these are schools that are explicitly believed to share specific core areas with the university. So we explicitly have one school for research and development, where we conduct research projects and try to feed that back into regular school classes. So you could say that we conduct research and at the same time contribute to school development." (Transcript No. 1, lines 463-469).

In this context, the researcher reports on aspects of identification and reflection that shape mutual contact. Common knowledge may result from these communicative processes, and relational expertise is needed to manage the tensions that are part of the boundary crossing activities in the partnership. Reflection as a mechanism is required to learn from the field of school practice, and to realize that the scientific rationales he relies on do not completely account for the practical setting.

"That you don't feel you're coming out of university knowing something, have found something out and you 're telling the pedagogical field about it, but instead (...) 'I' $m$ coming along with my crazy ideas about supportive feedback - what does that look like?' and then I encounter the pedagogical field, and then I learn from them: This is great, what you did in your research, or your ideas on that, but that does not fit into our practice for this and that reason, because partly, you don't know what is going on here. " (Transcript No. 1, lines 735741).

Building on such an established network, the initiation of joint projects is facilitated. Small groups of the larger network meet at the boundary to work on specific aspects that are relevant for school practice as well as for educational research. Under such conditions, the mechanism of transformation is emerging. The following transcription illustrates the processrelated nature of transformative actions that may be established in such a project. In the course of this process, the establishment of new boundary practices becomes a joint mission emphasized by a linguistical shift from "I" and "the teachers" to "we" and "us" - with all 
participants engaging in brokering activities. The identification of different standpoints is taken as a starting point to reflect, coordinate, and subsequently transform current practices into new, hybrid ones.

"All three [teachers] have developed a system for working with checklists in their classrooms independently. I have observed that (...), and I observe certain deficits or problems, and the teachers also notice these deficits themselves. All of us are sort of dissatisfied with how it works, and now we are reflecting on possible formats to enter into a regular exchange together (...) And there is no point of contact in the usual sense, as if I were doing a teacher training course with the school - that's not what it is. Instead, we want to work together somehow, but we are not actually working together, because I work at the university and they work at the school. So now, we will have to invent something new first". (Transcript No.1, lines 783-803).

Even though the network seems quite stable, the inherent (here: the spacial) boundaries between school and university remain visible. They need to be transcended regularly to continue brokering activities. Even when the benefit of transformative practices for the participants is salient, challenges remain to integrate the requirements for being an acknowledged researcher and doing extensive brokering work.

"And that really is somewhat contradictory, because you know somehow that when after five years, you are evaluated by the university's steering comittee, what counts are third-party funds, and peer-reviewed papers as first or second author. And what counts less is what you have really changed about classroom practice, or where you were successful in convincing a teacher. " (Transcript No. 1, lines 658-664).

\section{Professional Development}

All participants of our study reported on activities of Professional Development (PD) in which they encounter the ,other' side. The kinds of PD activities that were reported by the respondents varied largely in duration, extent, contents and settings. Accordingly, unlike in joint projects or network activities, participation in PD activities does not seem to be related to the occurrence of specific learning mechanisms per se. Among the six respondents that reported on PD activities as their only form of interpersonal contact, three did not show any of the four learning mechanisms. Two showed identification and/or coordination, while one person showed identification, reflection, coordination and a wish for transformation.

From the statements of three teachers that did not report any of the learning mechanisms, it becomes visible that they regard research as something impersonal, reflected by denominations like "the research", or "the science". Resulting from this overgeneralized view 
about the other side, even the mechanism of identification is impeded, since the respondents do not regard researchers as individuals with have specific professional roles and histories. The statements of these subjects thus do not show any of the aforementioned social learning mechanisms. Instead, a notion of linear transfer from scientific findings into school practice predominates their thinking about the boundary- without a specification on who is supposed to actually do the transfer. A motivation for participating in PD activities may then look as follows:

"Well, you want to know about the findings from research, first of all, you want to perceive them, and second, you naturally want to partl/ implement them ". (Transcript No. 16, lines 302-303).

Contrary to this statement, many other participants call this notion of linear transfer into question when they reflect on their individual brokering activities in PD. In several instances, the respondents use identification and reflection to report on their experiences with PD. In many transcripts operating with these learning mechanisms, subjects explicitly state that carrying scientific knowledge to a practice-oriented audience would be to take too narrow a view for doing brokering work.

"Teachers in school practice - Actually, I am not sure whether I want to deliver something to them. Honestly, not. Well, I don't feel that I am in a position for doing that - that I am the one that is entitled to convey something. But instead, rather seeing it as - actually, I would like to see it as an exchange. " (Transcript No. 8, lines 427-430).

The participants that reported PD activities as their only interpersonal contact at the boundary of educational research and school practice, emphasize their difficulties to reach the ,other' side during their regular professional work, hindering them to engage in brokering activities, as the following excerpts exemplify.

"I don't know. I figure that when there are any research studies related to instructional topics or anything like that, there are often teachers listed in the appendices. I don't know how you get there! I would also be interested to say: I would/ could I join in with some of the work. Or I would/ but I wouldn't know - as I said - I wouldn't know who to approach to say 'Perhaps I might have something to say about such and such a topic as well. (...) Perhaps there is a lot out there, but I really wouldn't know. Well. I would appreciate it if perhaps research focusing on school would approach us a bit more. Perhaps to try to bring us in a bit more."

(Transcript No. 18, lines 533-546). 
"I think that both systems are completely separate. (...) And for me as an outsider, I have the feeling that I do not really get in contact with schools, because I do not know their communities and boards, because somehow/ people don't mix. And I simply know that schools are extremely busy all the time, you hardly even get any principal on the phone. They kind of ward everything off that sounds like entailing extra work. I believe that [... educational research] is regarded as something that is put on top of everything else, and not as something that is somehow integrated." (Transcript No. 9, lines 489-511).

Both teachers and researchers that report PD activities as their only possibility of interpersonal contact share the notion of working in two separate worlds with only few connections with the respective other. In the absence of network activities or joint projects, brokering activities seem less likely to be carried out by individuals. When a regular interpersonal contact enabling co-constructive work at the boundary is not part of the professional context, hurdles are often regarded as too high to be overcome individually.

However, Professional Development as a setting also bears the potential for the occurrence of learning mechanisms when it is conceptualized similar to joint projects that include coconstructive practices, and when it is complemented by other forms of interpersonal contact. In a year-long PD course originating from a (researcher-led) research project, teachers and researchers extensively discussed about classroom videos, and this resulted in a wish for transformative practices at the boundary. As table 1 shows, respondent No. 2 had expressed the three mechanisms of identification, reflection, and coordination as outcomes of the researcher-led project she was engaged with, and conducting a PD course as a follow-up of her project work, led her to the following conclusion.

"A professional development course for teachers, voluntarily. Where we could really work together with them, in a project to develop instructional practices, partly on the basis of the video data that we had collected. And I found that really inspiring, to really discuss with them. Well, before doing that, I only had the videos and questionnaires. And in these PD courses, I had them right in front of me, face-to-face, you know? I was able to discuss with them, about their ideas of [research topic]. And yes, that's a highlight for me. ... And still, my dream is ... That you can really do research, let's say interventions, in mixed teams. Well, so that really teachers are part of the research team. Where you can try things out. " (Transcript No. 2, lines 689-709).

\section{Discussion}

This paper connects research on partnerships between educational researchers and school practice to the theoretical approach of boundary crossing (Akkerman \& Bakker, 2011) with a 
focus on four learning mechanisms (identification, reflection, coordination, and transformation) that may emerge when people cross professional boundaries.

Summing up the key findings from our study, brokering activities by educational researchers and teachers are most likely to occur in three settings, being (a) research projects in schools, (b) network activities, and (c) professional development. Generally, all three settings allow for the learning mechanisms of identification, reflection and coordination to emerge. Still, respondents that solely experience themselves brokering in the setting of PD activities are less likely to learn about the 'other side' via all three mechanisms. Additionally, the mechanism of transformation is only being realized in settings that enable people to establish forms of joint project work where researchers and practitioners engage in mutual discussion, for example by jointly analyzing classroom data.

In line with the work of Edwards \& Stamou (2017), these findings suggest that it is important to regard research and practice as a potential field of knowledge exchange rather than an issue of impact from research to practice in a linear sense (see also Coburn \& Stein, 2010). Rather than transferring research findings to practice settings, joint learning needs co-constructive practices and joint knowledge generation. The data in this study illustrate that by realizing this kind of work, even transformation as the most ambitious goal for learning can be realized, at least in some instances.

Moreover, our data point out that only few of the reported interpersonal contacts fulfill the criteria for RPPs set up by Coburn \& Penuel (2016). Brokering activities are mostly characterized by high individual effort and commitment, sometimes in the absence of reliable institutional support systems. Still, joint learning may emerge even in these small-scale activities. For supporting brokering activities at the boundary of educational research and school practice, installing co-constructive practices seems crucial. When researchers and teachers get opportunities to discuss issues relevant for both sides, and engage in developing shared problem-spaces and common knowledge, joint learning may emerge that can subsequently transform how people regard the interface of educational research and schools. In line with other research, transformation as a learning mechanism requires intense and, in most instances, long-term boundary work (Akkerman \& Bruining, 2016; Edwards \& Stamou, 2017). Our findings also stand in accordance with the theoretical assumptions on boundary crossing, assuming that the four learning mechanisms partly build up on each other. Whereas identification and coordination can stand alone, reflection and, in particular, transformation 
need the other mechanisms as precursors or mediators. A wish for transformation only emerged when the other three mechanisms were at play.

Network activities can serve as a context to facilitate access to these intense forms of joint work-based learning, as it connects people and institutions over a longer period of time. In principle, professional development activities may serve this function as well when they are set up as longer-term contacts and include co-constructive elements. However, PD activities are often experienced as single-time events which are not sufficient to build common knowledge and relational expertise for successful brokering activities to take place. Adding to Edwards \& Stamou's (2017) work, the researchers in our sample expressed similar ambiguities in acting as brokers at the boundary. The ones who engage in this field still consider them as "undercover activities" (p. 273) that in many respects sharply contrast with the demands by the research system in which they operate.

\section{Limitations}

For several reasons, our findings are limited in their explanatory power. First, the small-scale sample that comprised participants of one specific project at the boundary (a joint workshop preceded by individual interviews which were the basis of the present study) is by no means representative of any wider population. Specifically, the sample cannot be regarded as saturated neither pertaining to the contextual conditions nor to the learning mechanisms expressed. Our findings may therefore not be generalized, and should be interpreted with caution.

A second limitation results from the decision to not explicitly cue participants for each of the four learning mechanisms to assess them in detail, as we were using a semi-structured interview procedure with more general questions to let participants narrate. We thus cannot be certain about whether respondents did not display any of the mechanisms simply because they did not explicitly remember them in the interview. Moreover, especially for complex learning processes such as transformation or reflection, participants sometimes only named a few of the features that constitute this mechanism. We therefore intensely discussed the codings between the first and second author of this study, and in cases of any doubt we decided to code for a learning mechanism when it was at least partly explicated. Furthermore, the setup of our interview study did not allow for a differentiation between sub-categories of learning mechanisms as they were proposed by Akkerman \& Bakker (2011). We can thus not be certain whether an expression that explicitly expressed the sub-category of "othering" would 
also entail the second sub-category "legitimating coexistence", even when in most instances, that second aspect of identification was implicitly conveyed in the interviews. Due to the structure of the available data, we had to refrain from a more detailed coding procedure and thus limited ourselves to distinguish between the four main categories to characterize the learning of individual brokers. Furthermore, along with our focus on the individuals that we interviewed, we cannot fully grasp the multilevel nature of boundary learning proposed by Akkerman and Bruining (2016), even though some of the excerpts do indicate that changes on an institutional level may have been triggered by various individual brokering activities. Third, as we only conducted the interviews once with each person, we do not know how learning mechanisms add up on each other, or how sustainable partnerships develop. To access such developmental effects, longitudinal studies can provide far more insight than our study does (e.g., Akkerman \& Bruining, 2016; Jones et al., 2016).

Bearing these limitations in mind, our study provides empirical support for the claim that individual brokering activities in various settings of interpersonal contact may reveal learning potentials at the boundary between educational research and school practice. To allow deep learning beyond mere identification or single aspects of coordination, results from this study point to the necessity of establishing settings that allow for mutual exchange and a continuous negotiation between the two distinct fields of research and practice. Further research should address potential outcomes of such forms of sustained collaboration, as Coburn and Penuel (2016) have called for in their recent review. Moreover, an investigation of whether people who regularly participate in brokering activities can transfer newly established boundary practices or competencies onto different settings - e.g., using relational expertise that was acquired in the course of joint projects - would be needed (see also Edwards, 2017).

\section{Conclusion}

The decision for teachers and researchers to engage in brokering at the boundary of educational research and school practice is likely to be influenced by their professional and personal histories as well as by the context in which they operate. Despite the inherent tensions that brokers struggle with, our findings can be regarded as an encouragement for joint work that makes mutual learning worthwhile for the participants. On the basis of coconstructive relationships, there is indication in our data that learning at the boundary seems an attainable goal, even when brokers are faced with various obstacles. Likewise, the body of theoretical and empirical work compiled in this study indicates that if people do not 
experience forms of mutual interpersonal contact, the learning mechanism of transformation is unlikely to emerge. In regarding joint work as a meaningful extension of the professional identities of teachers as well as of educational researchers, brokering activities may be one lever to reduce the gap between research and practice. 


\section{References}

1. Akkerman, S. F., \& Bakker, A. (2011). Boundary crossing and boundary objects. Review of Educational Research, 81(2), 132-169. doi:10.3102/0034654311404435

2. Akkerman, S. F., \& Bruining, T. (2016). Multi-level boundary crossing in a professional development school partnership. Journal of the Learning Sciences, 25(2), 240-284. doi:10.1080/10508406.2016.1147448

3. Akkerman, S. F., Bronkhorst, L. H., \& Zitter, I. (2013). The complexity of educational design research. Quality and Quantity, 47(1), 421-439. doi:10.1007/s11135-011-9527-9

4. Anderson, T., \& Shattuck, J. (2012). Design-based research: A decade of progress in education research? Educational Researcher, 41(1), 16-25. doi:10.3102/0013189X11428813

5. Bakx, A., Bakker, A., Koopman, M., \& Beijaard, D. (2016). Boundary crossing by science teacher researchers in a PhD program. Teaching and Teacher Education, 60, 76-87. doi:10.1016/j.tate.2016.08.003

6. Brown, E. C., Hawkins, J. D., Arthur, M. W., Briney, J. S., \& Fagan, A. A. (2011). Prevention service system transformation using communities that care. Journal of Community Psychology, 39, 183-201. doi:10.1002/jcop.20426

7. Coburn, C. E., \& Penuel, W. R. (2016). Research-practice partnerships in education: Outcomes, dynamics, and open questions. Educational Researcher, 45(1), 48-54. doi:10.3102/0013189X16631750

8. Coburn, C. E., Honig, M. I., \& Stein, M. K. (2009). What's the evidence on districts' use of evidence? In J. D. Bransford, D. J. Stipek, N. J. Vye, L. M. Gomez, \& D. Lam (Eds.), The role of research in educational improvement (pp. 67-87). Cambridge: Harvard Education Press.

9. Coburn, C. E., Penuel, W. R., \& Geil, K. (2013). Research-practice partnerships: A strategy for leveraging research for educational improvement in school districts. New York: William T. Grant Foundation.

10. Coburn, C., \& Stein, M. (Eds.). (2010). Research and practice in education. Lanham: Rowman \& Littlefield.

11. Cochran-Smith, M., \& Lytle, S. L. (1999). Relationships of knowledge and practice: Teacher learning in communities. Review of Research in Education, 24(1), 249-305. doi: $10.2307 / 1167272$

12. Dresing, T., \& Pehl, T. (2013). Praxisbuch interview, transkription \& analyse. Anleitungen und regelsysteme für qualitativ forschende [Manual of interview, transcription, and analysis. Instructions and guidelines for qualitative researchers]. Retrieved from http://www.audiotranskription.de/download/praxisbuch_transkription.pdf?q=praxisbuchtranskription.pdf 
13. Edwards, A. (2012). The role of common knowledge in achieving collaboration across practices. Learning, Culture and Social Interaction, 1(1), 22-32.

doi:10.1016/j.lcsi.2012.03.003

14. Edwards, A. (Ed.) (2017). Working relationally in and across practices. A culturalhistorical approach to collaboration. New York, NY: Cambridge University Press.

15. Edwards, A., \& Stamou, E. (2017). Relational approaches to knowledge exchange in social science research. In A. Edwards (Ed.), Working relationally in and across practices. A cultural-historical approach to collaboration. (pp. 265-282). New York, NY: Cambridge University Press.

16. Edwards, A., Lunt, I., \& Stamou, E. (2010). Inter-professional work and expertise: New roles at the boundaries of schools. British Educational Research Journal, 36, 27-45.

17. Engeström, Y. (1987). Learning by expanding. An activity-theoretical approach to developmental research. Helsinki: Orienta-Konsultit.

18. Hammersley, M. (2013). The myth of research-based policy and practice. London: Sage.

19. Jones, C. (2010). Finding a place in history: Symbolic and social networks in creative careers and collective memory. Journal of Organizational Behavior, 31, 726-748.

20. Jones, M., Hobbs, L., Kenny, J., Campbell, C., Chittleborough, G., Gilbert, A., ... Redman, C. (2016). Successful university-school partnerships: An interpretive framework to inform partnership practice. Teaching and Teacher Education, 60, 108120. doi:10.1016/j.tate.2016.08.006

21. Kaslow, N. J. (2015). Translating psychological science to the public. American Psychologist, 70(5), 361-371. doi:10.1037/a0039448

22. King, G., Servais, M., Forchuk, C., Chalmers, H., Currie, M., Law, M., ... Kertoy, M. (2010). Features and impacts of five multidisciplinary community-university research partnerships. Health \& Social Care in the Community, 18(1), 59-69. doi:10.1111/j.13652524.2009.00874.x

23. Kuckartz, U. (2014). Qualitative inhaltsanalyse. Methoden, praxis, computerunterstützung [Qualitative content analysis. Methods, practice, computer-aided analysis] (2nd ed.). Weinheim: Beltz Juventa.

24. Metzler, M. M., Higgins, D. L., Beeker, C. G., Freudenberg, N., Lantz, P. M., Senturia, K. D., ... Softley, D. (2003). Addressing urban health in Detroit, New York City, and Seattle through community-based participatory research partnerships. American Journal of Public Health, 93(5), 803-811. doi:10.2105/ajph.93.5.803

25. Nutley, S., Walter, I., \& Davis, H. (2007). Using evidence: How research can inform public services. Bristol, UK: Policy Press.

26. Penuel, W. R., Allen, A.-R., Coburn, C. E., \& Farrell, C. (2015). Conceptualizing research-practice partnerships as joint work at boundaries. Journal of Education for Students Placed at Risk, 20, 182-197. doi:10.1080/10824669.2014.988334 
27. Prewitt, K., Schwandt, T., \& Straf, M. L. (Eds.). (2012). Using science as evidence in public policy. Washington: National Academies Press. doi:10.17226/13460

28. Sannino, A. (2016). Double stimulation in the waiting experiment with collectives: Testing a Vygotskian model of the emergence of volitional action. Integrative Psychological and Behavioral Science, 50(1),142-73. doi: 10.1007/s12124-015-9324-4

29. Sannino, A., \& Engeström, Y. (2017). Relational agency, double stimulation, and the object of activity: An intervention study in a primary school. In A. Edwards (Ed.), Working relationally in and across practices. A cultural-historical approach to collaboration. (pp. 265-282). New York, NY: Cambridge University Press.

30. Shonkoff, J. P., \& Bales, S. N. (2011). Science does not speak for itself: Translating child development research for the public and its policymakers. Child Development, 82(1), 17-32. doi:10.1111/j.1467-8624.2010.01538.x

31. Suchman, L. (1993). Working relations of technology production and use. Computer Supported Cooperative Work, 2, 21-39. doi:10.1007/bf00749282

32. Tanggaard, L. (2007). Learning at trade vocational school and learning at work: Boundary crossing in apprentices' everyday life. Journal of Education and Work, 20, 453-466.

33. Walker, D., \& Nocon, H. (2007). Boundary-crossing competence: Theoretical considerations and educational design. Mind, Culture, and Activity, 14(3), 178-195.

34. Wenger, E. (1998). Communities of practice: Learning, meaning, and identity. New York, NY: Cambridge University Press. doi: 10.1017/CBO97805 
Table 1: Reports on learning mechanisms and interpersonal contact at the boundary of educational research and school practice

\begin{tabular}{|c|c|c|c|c|c|c|c|c|c|c|c|}
\hline \multirow{3}{*}{$\begin{array}{l}\text { Subject } \\
\text { No. }\end{array}$} & \multirow{3}{*}{$\operatorname{Sex}$} & \multirow{3}{*}{ Profession } & \multicolumn{4}{|c|}{ Reported learning mechanisms at the boundary } & \multicolumn{5}{|c|}{ Forms of interpersonal contact at the boundary } \\
\hline & & & \multirow[t]{2}{*}{ Identification } & \multirow[t]{2}{*}{ Reflection } & \multirow[t]{2}{*}{ Coordination } & \multirow[t]{2}{*}{ Transformation } & \multicolumn{2}{|c|}{ Research projects in schools } & \multirow{2}{*}{$\begin{array}{l}\text { Network } \\
\text { activities }\end{array}$} & \multirow{2}{*}{$\begin{array}{c}\text { Professional } \\
\text { Development } \\
\text { activities }\end{array}$} & \multirow{2}{*}{$\begin{array}{c}\text { Further interpersonal } \\
\text { contact at the } \\
\text { boundary }\end{array}$} \\
\hline & & & & & & & $\begin{array}{l}\text { researcher- } \\
\text { led }\end{array}$ & joint & & & \\
\hline 1 & male & researcher & yes & yes & yes & yes & -- & $\mathrm{X}$ & $\mathrm{X}$ & $\mathrm{X}$ & \\
\hline 4 & male & researcher & yes & yes & yes & yes & -- & $\mathrm{X}$ & $\mathrm{X}$ & $\mathrm{X}$ & \\
\hline 5 & male & researcher & yes & yes & yes & yes & -- & $\mathrm{X}$ & & $\mathrm{X}$ & $\begin{array}{l}\text { Longer-term } \\
\text { counselling } \\
\text { relationship with } \\
\text { schools }\end{array}$ \\
\hline 7 & male & researcher & yes & yes & yes & yes & -- & $X$ & -- & $X$ & \\
\hline 8 & female & researcher & yes & yes & yes & yes & -- & $\mathrm{X}$ & -- & $\mathrm{X}$ & $\begin{array}{l}\text { Longer-term } \\
\text { counselling } \\
\text { relationship with a } \\
\text { school }\end{array}$ \\
\hline 15 & female & practitioner & yes & yes & yes & $\begin{array}{c}\text { wish for } \\
\text { transformation }\end{array}$ & $\mathrm{X}$ & -- & $\mathrm{X}$ & $\mathrm{X}$ & \\
\hline 9 & female & researcher & yes & yes & yes & $\begin{array}{c}\text { wish for } \\
\text { transformation }\end{array}$ & -- & -- & -- & $\mathrm{X}$ & \\
\hline 2 & female & researcher & yes & yes & yes & $\begin{array}{l}\text { wish for } \\
\text { transformation }\end{array}$ & $\mathrm{X}$ & -- & -- & $\mathrm{X}$ & \\
\hline 13 & male & practitioner & yes & yes & yes & no & -- & $\mathrm{X}$ & $\mathrm{X}$ & $\mathrm{X}$ & \\
\hline 6 & male & researcher & yes & yes & yes & no & $\mathrm{X}$ & -- & $X$ & $X$ & \\
\hline 10 & female & researcher & yes & yes & yes & no & -- & -- & $\mathrm{X}$ & $\mathrm{X}$ & \\
\hline 3 & male & researcher & yes & yes & yes & no & -- & -- & -- & $\mathrm{X}$ & $\begin{array}{l}\text { Several one-time } \\
\text { counselling activities }\end{array}$ \\
\hline 18 & female & practitioner & yes & no & yes & no & -- & -- & -- & $\mathrm{X}$ & \\
\hline 14 & female & practitioner & yes & no & no & no & -- & -- & -- & $\mathrm{X}$ & \\
\hline 12 & female & practitioner & no & no & yes & no & $\mathrm{X}$ & -- & -- & $\mathrm{X}$ & \\
\hline 16 & male & practitioner & no & no & no & no & -- & -- & -- & $\mathrm{X}$ & \\
\hline
\end{tabular}




\begin{tabular}{|c|c|c|c|c|c|c|c|c|c|c|}
\hline \multicolumn{11}{|c|}{ practitioner } \\
\hline 20 & female & practitioner & no & no & no & no & -- & -- & -- & $\mathrm{X}$ \\
\hline
\end{tabular}


Table 2: Coding Scheme for analyzing reported learning mechanisms at the boundary between educational research and school practice

\begin{tabular}{lcl}
\hline $\begin{array}{l}\text { Learning } \\
\text { mechanism }\end{array}$ & $\begin{array}{l}\text { Key ideas (according to Akkerman } \\
\text { \& Bakker, 2011; Akkerman \& } \\
\text { Bruining, 2016) }\end{array}$ & Description \\
\hline Identification & 1. Othering & $\begin{array}{l}\text { Definition of one specific practice, delineating } \\
\text { how it differs from another practice, a process } \\
\text { called othering. Moreover, a second process } \\
\text { constitutes identification, a process called }\end{array}$ \\
& & $\begin{array}{l}\text { legitimating coexistence, meaning that an } \\
\text { individual can consider both practices to differ } \\
\text { from each other, with each providing their own } \\
\text { intrinsic value and specific contribution. }\end{array}$ \\
& &
\end{tabular}

Examples of data

\begin{tabular}{ll}
\hline Coordination & 1. Communicative Connection \\
& 2. Efforts of translation \\
3. Increasing boundary \\
\end{tabular}

Reported activities at the boundary that aim to make joint work more efficient, and facilitate a continuous movement between different sites. It entails establishing a communicative connection, e.g., by means of translation efforts, and enhancing boundary permeability from both sides. Finally, routinization processes in work between two sites of practice characterize the learning mechanism of coordination.

Because only the practitioners can really do the teaching well. But they cannot do the research. And vice versa, I cannot teach well (...) But they (the teachers) are not on the cutting edge.

Coordination addresses each of the partners with their specific tasks. Clear boundaries between research tasks and practice tasks remain visible.

Boundary objects can be used to facilitate coordination.

Our coordinator, she works day and night/ she has to make phone calls and emails and so on. This is a huge, complex thing. But, what we always try is to make them understand that we actually see each other as partners, but not on the... with the same skill-sets. So that it is actually clear that they have the skills to deliver lessons, to advise the students and so on. And we have the research skills.

And I think it is a good approach to link and interrelate these two fields of work with each other, for example by a regular exchange forum.

Reflection allows subjects to recognize

differences between practices and relate them to

Well, I learn from the teachers' questions, also the bidirectional perceptions of the participants from their critical questions. I learn that it is in a boundary crossing endeavor. Reflection
1. Perspective making
2. Perspective taking 
involves making one's own perspective explicit, and reflecting it in the light of the other

perspective, while at the same time taking the other perspective into account for a more thorough understanding of a problem.

Reflection builds on the mechanism of identification. Reflection is only coded when reciprocal viewpoints, and expectations are reported and elaborated on. (...),how easily that same thing can be misunderstood by the teachers as an unwanted interference into their daily practice.

\section{A process that is initiated by individuals or} systems that are confronted with a problem at the boundary, and a subsequent recognition of a shared problem space by the involved parties. To overcome the problem in a joint action, measures are taken to establish hybrid practices and embed them into collaborative routines so that continuous dialogical work at the boundary can be maintained.
And this is really a kind of bottom-up research. We have put together five student researchers and one teacher. The teacher was deputized with two hours per week for university work. Which has been a huge privilege, and still is. And then all these people together have investigated one specific problem or perspective in the classroom of that teacher.
6. Continuous joint work at the boundary

\section{Wish for \\ transformation}

This category is coded when respondents report aspects of transformation as something that would enrich their professional field.
I would appreciate if researchers would be more in schools. Someone coming into our classes with a research project in our daily classes - not that I hand him my class and he is doing something spectacular with it - but instead, analyzing real-life classes, analyzing and observing it in a permanent exchange with the teachers. Because I really feel that research could bring something in that would benefit daily instruction in schools. 